\title{
偶联噻吩引入对三苯胺成膜性提高及电致变色性能增强
}

\author{
欧阳密 付志艳吕晓静陈欢乐 胡 涁 夏旭峰 张 诚 \\ (浙江工业大学化学工程与材料学院, 绿色化学合成国家重点实验室培育基地, \\ 科技部能源材料及应用国际科技合作基地, 杭州 310014)
}

\begin{abstract}
摘要：合成了一种以三苯胺(TPA)为核、偶联噻吩为端基的有机小分子 4,4'4"-三[4-(2-联噻吩基)苯基]胺 (TBTPA), 并通过电化学聚合得到其相应的聚合物PTBTPA. 运用电化学工作站和紫外-可见光谱仪连用对该聚 合物膜的光谱电化学性质进行了测试. 与先前已报道的三[4-(2-噻吩基)苯基]胺(TTPA)相比, TBTPA 呈现出更 好的电化学氧化还原活性. 在电化学聚合过程中, PTBTPA膜呈现出更好的成膜性能且在不同的电位下可以显 示三种颜色(深橙色、橄榄绿、暗灰色). 此外, 光谱电化学测试结果表明, 与先前报道的PTTPA 相比, PTBTPA 具 有更好的电致变色(EC)性能, 高的颜色对比度 $(44.7 \%)$, 更高的透射对比度 $(\Delta T$, 在 720 及 $1100 \mathrm{~nm}$ 处对比度分 别为 $49 \%$ 和 $52 \%$ )及较快的响应时间(在 $720 \mathrm{~nm}$ 时为 $0.93 \mathrm{~s}$, 在 $1100 \mathrm{~nm}$ 时为 $0.91 \mathrm{~s}$ ), 同时, PTBTPA具有更高 的着色效率 $\left(720 \mathrm{~nm}\right.$ 时为 $198 \mathrm{~cm}^{2} \cdot \mathrm{C}^{-1}, 1100 \mathrm{~nm}$ 时为 $285 \mathrm{~cm}^{2} \cdot \mathrm{C}^{-1}$ ). 从扫描电镜(SEM)照片得出 PTBTPA薄膜 呈现微球颗粒堆积形貌, 颗粒粒径为 $500 \mathrm{~nm}$ 左右, 比 PTTPA 的粒径小. 良好的性能表明 PTBTPA在电致变色 器件上具有很大的应用前景.
\end{abstract}

关键词: 三苯胺核; 电化学聚合; 成膜性; 电致变色; 高对比度 中图分类号: 0646

\section{Enhanced Film-Forming and Electrochromic Properties by Incorporating Bithiophene into Triphenylamine}

\author{
OUYANG Mi FU Zhi-Yan LÜ Xiao-Jing CHEN Huan-Le HU Bin \\ XIA Xu-Feng ZHANG Cheng*
}

(State Key Laboratory Breeding Base of Green Chemistry-Synthesis Technology, International Science \& Technology Cooperation Base of Energy Materials and Application, College of Chemical Engineering and Materials Science, Zhejiang University of Technology, Hangzhou 310014, P. R. China)

\begin{abstract}
An electrochromic (EC) material consisting of triphenylamine (TPA) core and peripheral bithiophene groups was synthesized, and the corresponding polymer was prepared by electrochemical oxidative cross-linking. The electrochemical properties of the 4,4',4"-tris[4-(2-bithienyl)phenyl]amine (TBTPA) monomer, and spectroelectrochemical and electrochromic properties of the poly $\left(4,4^{\prime}, 4^{\prime \prime}\right.$-tris [4-(2-bithienyl)phenyl]amine) (PTBTPA) polymer, were also systematically investigated. TBTPA possessing two thiophene groups exhibited better redox reversibility than that of the reported tris[4-(2-thienyl)phenyl] amine (TTPA). During electropolymerization, PTBTBA exhibited excellent film-forming property and strong adhesion to the ITO electrode, satisfying the basic requirements for achieving high EC performance. PTBTPA exhibited three different colors under various potentials (darkorange, olivegreen and dimgray). PTBTPA indicated enhanced EC performances and a higher contrast ratio of $44.7 \%$ compared with that of
\end{abstract}

\footnotetext{
Received: December 7, 2012; Revised: February 27, 2013; Published on Web: February 28, 2013.

"Corresponding author. Email: czhang@zjut.edu.cn; Tel: +86-571-88320253.

The project was supported by the National Key Basic Research Program of China (973) (2010CB635108, 2011CBA00700), International Science and Technology Cooperation Program, China (2012DFA51210), and National Natural Science Foundation of China (51203138, 51273179). 国家重点基础研究发展计划(973)前期专项项目(2010CB635108, 2011CBA00700), 国际科技合作重点项目计划(2012DFA51210)及国家自然 科学基金(51203138, 51273179)资助
}

C. Editorial office of Acta Physico-Chimica Sinica 
reported poly(tris[4-(2-thienyl)phenyl]amine) (PTTPA). PTBTPA also exhibited a higher optical contrast $(\Delta T)$ of $49 \%$ and $52 \%$ at 720 and $1100 \mathrm{~nm}$, respectively. It showed fast switching responses of 0.93 and $0.91 \mathrm{~s}$ at 720 and $1100 \mathrm{~nm}$, respectively, and higher coloration efficiencies of 198 and $285 \mathrm{~cm}^{2} \cdot \mathrm{C}^{-1}$ at 720 and $1100 \mathrm{~nm}$, respectively. Scanning electron microscopy (SEM) revealed that the PTBTPA film surface had accumulated clusters of globules, which were smaller than those of PTTPA. The superior performances of PTBTPA suggested its potential as an efficient EC material.

Key Words: Triphenylamine core; Electropolymerization; Film-forming; Electrochromism; High optical contrast

\section{Introduction}

Electrochromism is a phenomenon that optical changes occur in chemical materials by a reversible electrochemical process. $^{1-3}$ For electrochromic (EC) conjugated polymers (CPs), the electrochromism is related to the changing of band gaps during the doping-dedoping process. Thus, it is necessary to achieve different kinds of EC properties via adjusting the electronic characters of the $p$-orbit along the neutral polymer backbone. ${ }^{4}$ Electrochromic materials have been attracting much interest for several decades, as they have several important applications, such as energy-saving "smart" windows, ${ }^{5}$ rear-view mirrors, ${ }^{6}$ electrochromic displays, ${ }^{7}$ and electronic paper or electrochromic painting. ${ }^{8}$ At present, there is significant attention in the design of new EC materials combining polyelectrochromic property, high contrast ratio (a large change in percent transmittance between the colored and bleached states), and fast switching time. ${ }^{9}$ In principles, high contrast ratio originates from significant changes of molecular planarity between two redox states. Thus by designing EC materials with twisted structure in neutral state and planiform structure in charged state, high contrast ratio in EC process would be realized.

Triphenylamine (TPA) derivatives have played important roles in organic optoelectronic devices ${ }^{10,11}$ and electrochromic applications during the past few decades due to their excellent charge transport properties, improved thermal and morphological stabilities..$^{12,13}$ TPA is a highly twisted molecule with twisted angle of $42^{\circ}$ to $44^{\circ}$, while under charge state (TPA $\left.{ }^{+}\right)$, TPA trends to become planar and extends the electron delocalization, leading to obvious color change. In this context, the introduction of TPA and its derivatives to EC materials has become one of the important approaches to obtain high contrast ratio. Usually the para-position of TPA needs to be protected by grafting electron-donating groups to prevent the oxidation coupling between electrogenerated radical cation of TPA to form tetraphenylbenzidine (TPB), ${ }^{14-17}$ which is considered as an undesired side reaction in EC process as it might lead to irreversible defect after several redox switches. ${ }^{18}$ Recently star-shaped molecule TTPA consisting of a TPA core substituted by thiophene functionalities was reported. ${ }^{19}$ PTTPA as EC material exhibited reasonable electrochromic characters. However, optical contrasts and the switching time could not simultaneously achieve excellent level. Herein we would present a novel EC material containing TPA core and peripheral bithiophene groups. In this study, a novel EC material (TBTPA) consisting of triphenylamine core and peripheral bithiophene groups was synthesized, and the corresponding polymer (PTBTPA) was prepared by electrochemically oxidative cross-linking. The electrochromic and spectroelectrochemical properties of PTBTPA were studied in detail. The differences of the spectroelectrochemical and electrochromic properties of PTBTPA and the reported PTTPA were also discussed.

\section{Experimental \\ 2.1 Materials}

Triphenylamine (Aladdin, 98\%), thiophene (Aladdin, 98\%), Mg (Aladdin, 99\%), $N$-bromosuccinimide (NBS) (ENERGY CHEMICAL, 98\%), tetrabutylammonium perchlorate (TBAP) (ACROS, 99\%) were used without further purification. Tetrahydrofuran (THF) (Hangzhou Shuanglin Chemical Reagent Company), chromatography grade acetonitrile (ACN), dichloromethane (DCM) (Hangzhou Shuanglin Chemical Reagent Company) were distilled from $\mathrm{CaH}_{2}$ and then stored over $4 \mathrm{~A}$ molecular sieves.

\subsection{Equipments}

${ }^{1} \mathrm{H}$ NMR spectra of synthesized products were recorded in $\mathrm{CDCl}_{3}$ solution on a Bruker AVANCE III $500 \mathrm{MHz}$ instrument (Bruker, Switzerland). The micro-Fourier-transform infrared (FTIR) spectra of monomers samples and the both polymer films samples at Neutral state peeled off from the indium tin oxide (ITO) electrode were pressed in a diamond cell and then examined between 4000 and $650 \mathrm{~cm}^{-1}$ by a Nicolet 6700 FTIR (Thermo Fisher Nicolet, USA), equipped with a nitrogen cooled MCT/A detector and a continuum infrared-microscope. A CHI $660 \mathrm{C}$ electrochemical analyzer (CH Instruments, China) was applied to conduct the electrochemical measurements. UV-Vis spectra were recorded on a Shimadzu UV-1800 UVVis spectrophotometer (Shimadzu, Japan). The transmittance and absorbance spectra were recorded in situ under various applied potentials. All experiments were carried out at room temperature. SEM measurements were taken by using a Hitachi S-4800 scanning electron microscopy (Hitachi, Japan). Digital photographs of the polymer films were obtained through the Canon E0S 500D (Canon, Japan) digital camera.

\subsection{Synthesis}


The synthetic approach of both monomers was outlined in Scheme 1.

\subsection{1 tris[4-(2-thienyl)phenyl]amine}

The monomer of tris[4-(2-thienyl)phenyl]amine (TTPA) was synthesized according to the reported method by palladiumcatalyzed cross-coupling reactions of tris(4-bromophenyl) amine with Grignard thiophene in THF for 12 h. ${ }^{20}$ Yield: 78\%. MS: $m / z=491\left(\mathrm{M}^{+}\right)$. FTIR (KBr): 1598, 1533, 1498, 1431, 1290 , $1274,1184,848,818,696 \mathrm{~cm}^{-1} .{ }^{1} \mathrm{H} \mathrm{NMR}\left(\mathrm{CDCl}_{3}, 500 \mathrm{MHz}\right) \delta$ : $7.08(\mathrm{t}, 3 \mathrm{H}), 7.14(\mathrm{~d}, 6 \mathrm{H}), 7.27(\mathrm{~d}, 6 \mathrm{H}), 7.54(\mathrm{~d}, 6 \mathrm{H})$.

\subsubsection{4,4',4"-tris[4-(2-bithienyl)pheny]amine}

The monomer of 4,4',4"-tris[4-(2-bithienyl)pheny]amine (TBTPA) was synthesized from Grignard thiophene and tris (4(2-bromothienyl)phenyl)amine which was obtained from bromination of PTBTPA. ${ }^{20}$ Yield: $70 \%$. MS: $m / z=737\left(\mathrm{M}^{+}\right)$. FTIR (KBr): 1596, 1518, 1457, 1322, 1290, 1182, 833, 796, 639 $\mathrm{cm}^{-1} .{ }^{1} \mathrm{H}$ NMR $\left(\mathrm{CDCl}_{3}, 500 \mathrm{MHz}\right) \delta: 7.04(\mathrm{dd}, 3 \mathrm{H}), 7.17(\mathrm{~m}$, 9H), 7.23 (m, 9H), $7.52(\mathrm{~d}, 6 \mathrm{H})$.

\subsection{Electrochemistry}

The electropolymerization and measurements were performed in a conventional three-electrode cell with an ITO-coated glass (CSG holding Co. LTD, $R_{\mathrm{s}} \leq 10 \Omega^{-1}$. the active area: 1.0 $\mathrm{cm} \times 2.0 \mathrm{~cm})$ as working electrode which was sequencely washed with ethanol, acetone and deionized water under ultrasonic before use, a platinum sheet and a double-junction $\mathrm{Ag} /$ $\mathrm{AgCl}$ electrode (silver wire coated with $\mathrm{AgCl}$ in saturated $\mathrm{KCl}$<smiles>Brc1ccc(N(c2ccc(Br)cc2)c2ccc(Br)cc2)cc1</smiles>

solution, $0.1 \mathrm{~mol} \cdot \mathrm{L}^{-1} \mathrm{TBAP}$ in $\mathrm{DCM} / \mathrm{ACN}$ ( $7: 3$, by volume) solution as the second junction) were applied as the counter electrode and the reference electrode, respectively. All the electrochemistry experiments were carried out at room temperature under $\mathrm{N}_{2}$ atmosphere.

\section{Results and discussion \\ 3.1 Electrochemical characterization and electropolymerization}

The redox behaviors of TTPA and TBTPA were investigated via cyclic voltammetry (CV) in DCM/ACN (7:3, by volume) using $0.1 \mathrm{~mol} \cdot \mathrm{L}^{-1}$ tetrabutylammonium perchlorate (TBAP) as supporting electrolyte with scan intervals $0 \mathrm{~V} / 1.4 \mathrm{~V}$ and $0 \mathrm{~V} /$ $1.2 \mathrm{~V}$ (vs $\mathrm{Ag} / \mathrm{AgCl}$ ), respectively (Fig.1a). In the first CV cycle, TTPA showed a couple of quasi-reversible redox peaks with the oxidative onset potential at $0.92 \mathrm{~V}$, oxidative peak at $1.12 \mathrm{~V}$, and reductive peak at $0.91 \mathrm{~V}$, respectively. By comparison, TBTPA exhibited a couple of reversible redox peaks with the oxidative onset potential at $0.87 \mathrm{~V}$, oxidative peak at 0.99 $\mathrm{V}$, and reductive peak at $0.88 \mathrm{~V}$, respectively. TBTPA showed lower oxidative onset potential than TTPA due to the enhanced conjugated length by adding another thiophene unit. ${ }^{21}$ TBTPA presented better redox reversibility compared with TTPA, which was benefit to the stability in EC process. On subsequent scans in the potential range from 0 to $1.4 \mathrm{~V}$ for TTPA and 0 to $1.2 \mathrm{~V}$ for TBTPA as shown in Fig. $1 \mathrm{~b}$, the redox peak

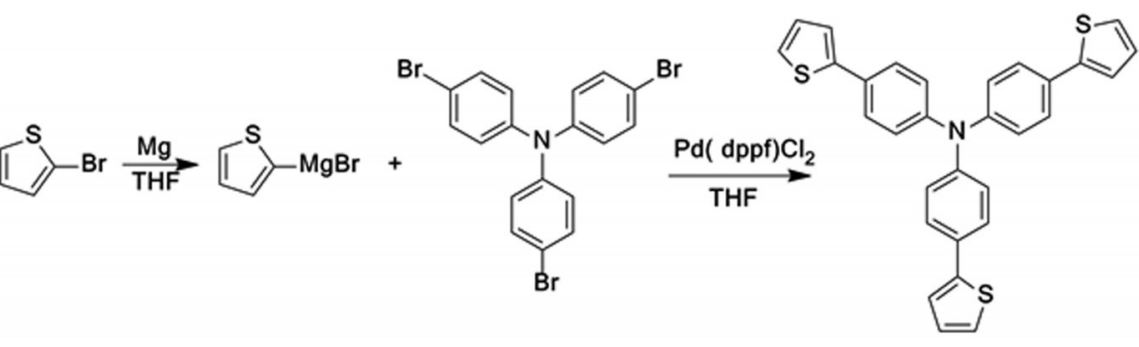

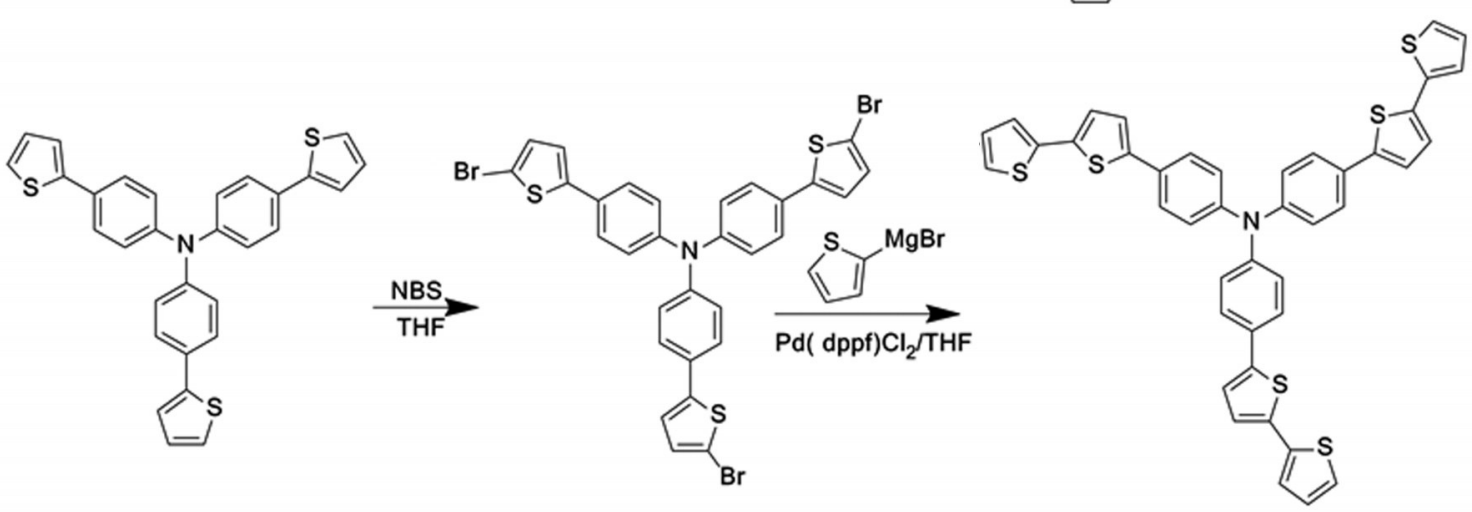

Scheme 1 Synthetic route and chemical structures for monomers TTPA and TBTPA 
current increased in the successive cycles, indicating cross-linking between the thiophene units and the growth of the film on the electrode. After washed in ACN solution, the PTTPA and PTBTPA film exhibited yellow and orange color, respectively. It was worth mentioning that PTTPA film was automatically peeled off from electrode even in polymerization process, which revealed poor adhesion to electrode. This phenomenon was commonly observed in other TPA based EC materials. The reason could be concluded as the low cross-linking efficiency because the oxidative potential of TPA was lower than that of thiophene, resulting in coulometric wastage. By contrast, the adhesion of PTBTPA film to electrode was very better, and no films peeled off from electrode even under sonication. We pointed out that the contact of film and electrode was a basic requirement to achieve high EC performance, and PTBTPA film exhibiting stronger adhesion to electrode clearly satisfy it.

The polymer films could be prepared via constant potentiostatic or via cyclic voltammetry, ${ }^{22}$ And the films of PTTPA and PTBTPA were synthesized via constant potential electrolysis on ITO electrode in DCM/ACN (7:3, by volume) containing $0.1 \mathrm{~mol} \cdot \mathrm{L}^{-1} \mathrm{TBAP}$ as supporting electrolyte and $1.5 \mathrm{mmol} \cdot \mathrm{L}^{-1}$ monomer. The redox behaviors of the films were carried out in DCM containing $0.1 \mathrm{~mol} \cdot \mathrm{L}^{-1} \mathrm{TBAP}$, which were presented in Fig.2a. PTTPA film showed better reversibility than the precur-
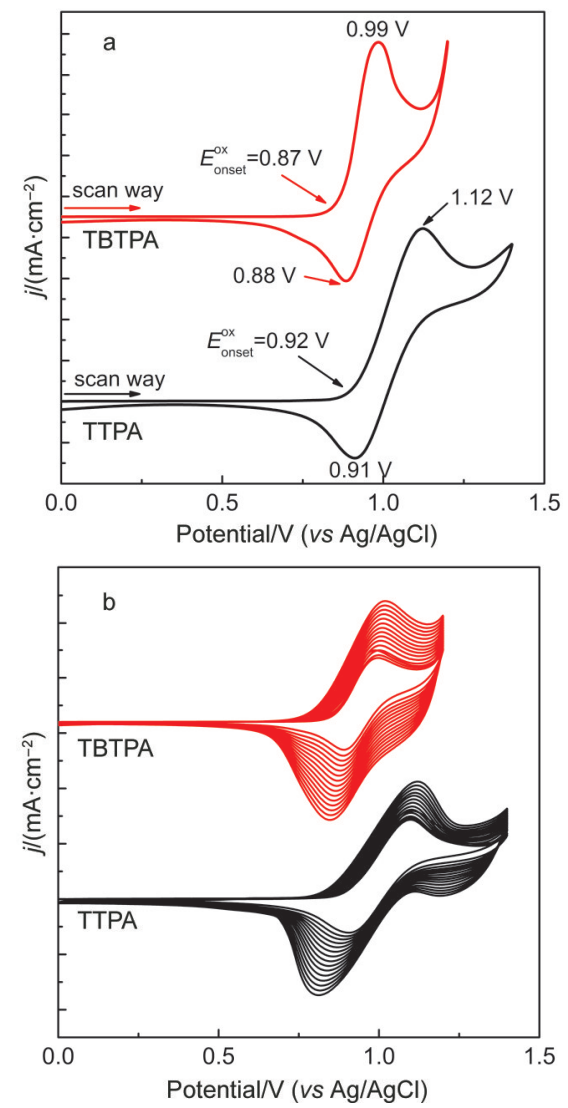

Fig.1 (a) The first $\mathrm{CV}$ cycles and (b) repeated cyclic voltammograms of $1.5 \mathrm{mmol} \cdot \mathrm{L}^{-1}$ TTPA and TBTPA on ITO electrode in $0.1 \mathrm{~mol} \cdot \mathrm{L}^{-1} \mathrm{TBAP}$ in DCM/ACN $(7: 3$, by volume) at a scan rate of $100 \mathrm{mV} \cdot \mathrm{s}^{-1}$ sor in solution with redox peaks at 0.91 and $1.07 \mathrm{~V}$, respectively. By comparison, the PTBTPA film showed more polarized redox peaks at 0.87 and $1.07 \mathrm{~V}$. This revealed that there were stronger interactions between electroactive groups (TPA, thiophene) and supporting electrolytes in PTBTPA film. The redox currents of PTTPA and PTBTPA films were correspondingly enhanced by the increase of scan rate (Fig.2b). Linear relationships between scan rates and current intensities indicated that all polymers were well adhered on ITO surface and the electrochemical processes were not limited by diffusion control. ${ }^{23,24}$

\subsection{Morphology}

The polymer films of PTTPA and PTBTPA were prepared through constant potential electrolysis in $0.1 \mathrm{~mol} \cdot \mathrm{L}^{-1} \mathrm{TBAP} /$ DCM containing relevant monomers on ITO electrodes. And the morphologies of the neutral PTTPA and PTBTPA films were investigated comparatively by SEM after dedoping at $-0.2 \mathrm{~V}$ for $30 \mathrm{~min}$ in a precursor-free solution.

As depicted in Fig.3, the surface of two polymer films showed an accumulation state of clusters of globules, and the approximate diameters of these globules were in the range of 500-1000 nm. But the diameter of PTBTPA (500 nm) was
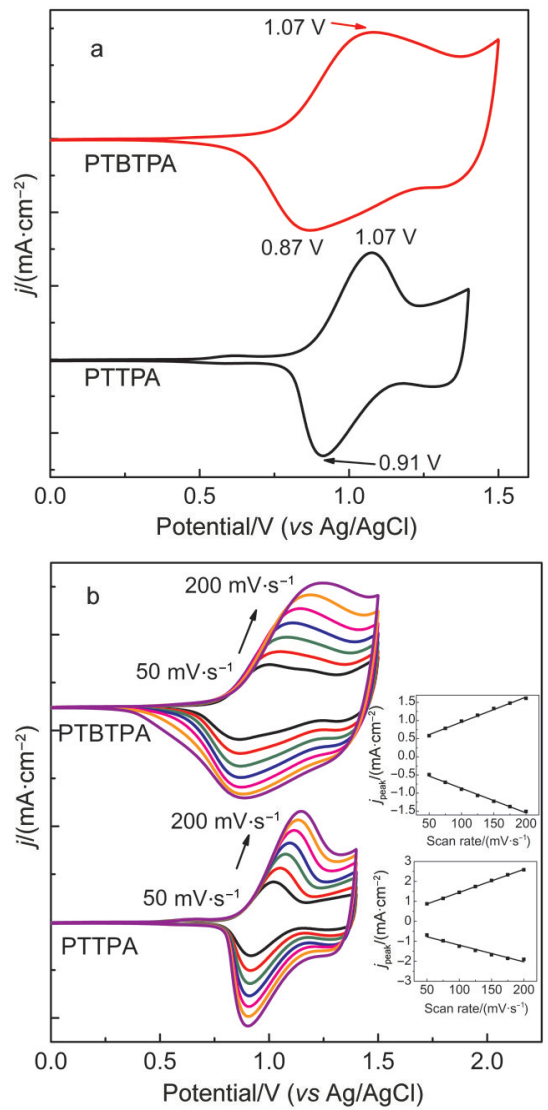

Fig.2 (a) CV curves of PTTPA and PTBTPA films in $0.1 \mathrm{~mol}$ -

$\mathrm{L}^{-1}$ TBAP in DCM/ACN (7:3, by volume) at a scan rate of $100 \mathrm{mV}$. $\mathbf{s}^{-1}$, (b) scan rate dependence of PTTPA and PTBTPA films on ITO electrode in $0.1 \mathrm{~mol} \cdot \mathrm{L}^{-1} \mathrm{TBAP}$ in DCM/ACN (7:3, by volume) solution

Inserts in figure $2 \mathrm{~b}$ show the corresponding peak current density $\left(j_{\text {peak }}\right)$ $v s$ scan rate. 

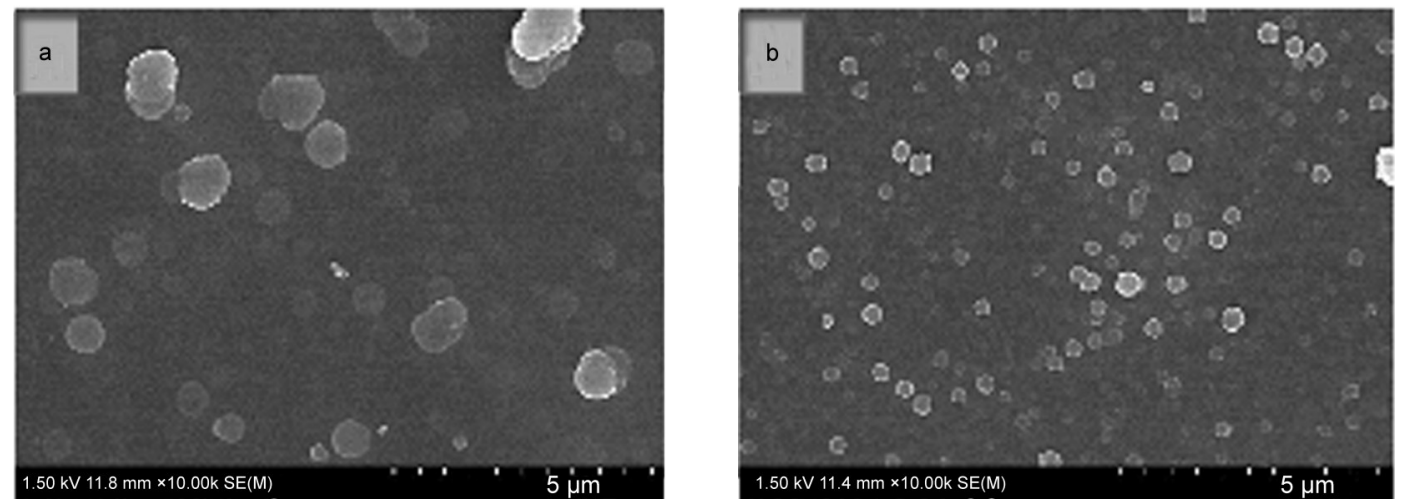

Fig.3 SEM images of (a) PTTPA film (1.40 V) and (b) PTBTPA film (1.20 V)

smaller than that of the PTTPA $(1000 \mathrm{~nm})$. The smaller size of globules of PTBTPA film could provide larger surface area and more contact interface for the insert/extract of charge carrier, which could offer the proof for the following enhanced electrochromic performance.

\subsection{Spectroelectrochemistry}

Spectroelectrochemical analyses of the resulted polymers were performed in order to investigate their optical and structural responses upon doping process, which proved the evolution of the charge carries in the structure..$^{25,26}$ The electrochromic absorption spectra were monitored by an UV-Vis spectrometer in DCM/ACN (7:3, by volume) containing $0.1 \mathrm{~mol} \cdot \mathrm{L}^{-1}$ TBAP as supporting electrolyte at different applied potentials.

As shown in Fig.4, TPA-based polymers displayed two transitions due to the TPA-thiophene hyperbranched structure. The largest energy transitions affected the colors of neutral films because the other transitions were not in the visible region dominantly. ${ }^{27}$ PTTPA and PTBTPA films showed the relative maximum absorption peak located at about 440 and $470 \mathrm{~nm}$ due to the $\pi \rightarrow \pi^{*}$ electron transition. Correspondingly, they exhibited yellow and orange color in their neutral state, respectively. The absorption peak of films was red-shifted with the increasing number of peripheral thiophene groups. The reason was mainly attributed to the appearance of 2,2'-bithienyl which located at the para-position of triphenylamine as donor group and possessed higher electron density and better conjugated character-

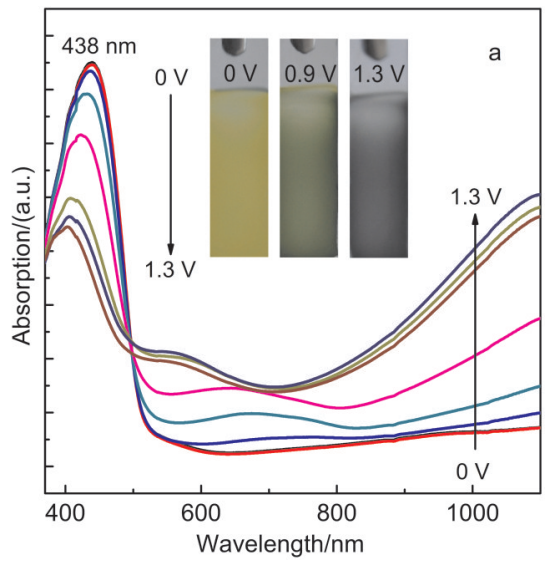

istic. With the increasing of oxidative potential, formation of charge carriers such as polarons and bipolarons in the PTTPA and PTBTPA backbones caused new absorption bands in near infrared (NIR) while absorptions for the neutral states were decreasing. The new broad absorption tails for PTTPA and PTBTPA were located at around 680 and $720 \mathrm{~nm}$, respectively. During the process, the PTTPA film showed the color changed from olivedrab to dimgry. On the other hand, the films of PTBTPA presented the color from olivegreen to dimgry (see Fig.4b). Moreover, PTBTPA exhibited better ratio of color change $(44.7 \%$, calculated by the change of maximum absorption intensity) than PTTPA (40.7\%), which revealed the enhanced peripheral thiophene group benefited for the doping process and the ratio of color change.

\subsection{Kinetic studies}

Optical contrasts were monitored at the maximum absorption of PTTPA and PTBTPA in order to characterize their response times and switching abilities. The films of PTTPA and PTBTPA (coated on ITO electrode with the polymerization charge of $0.02 \mathrm{C}$ ) were carried out with a residence time of $3 \mathrm{~s}$ at visible region $(680$ and $720 \mathrm{~nm})$. At NIR wavelength (1100 $\mathrm{nm})$, both the polymer films were carried out with a residence time of $4 \mathrm{~s}$. The switching time was defined as the time required for reach $95 \%$ of the full change in absorbance after the switching of the potential.

PTTPA film was switched between -0.2 and $1.3 \mathrm{~V}$. As de-

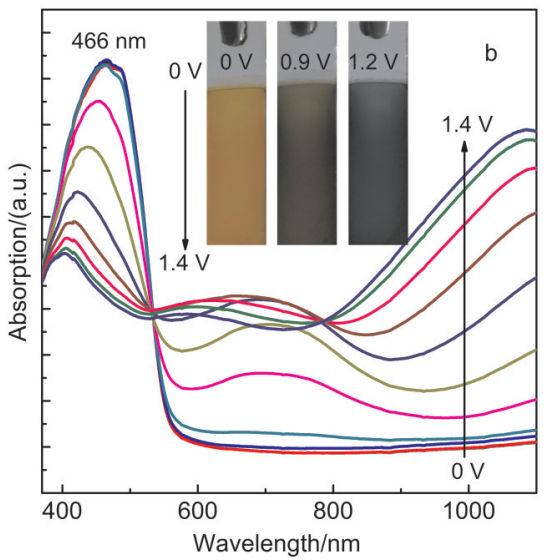

Fig.4 Spectroelectrochemical spectra of PTTPA and PTBTPA films as applied potentials 

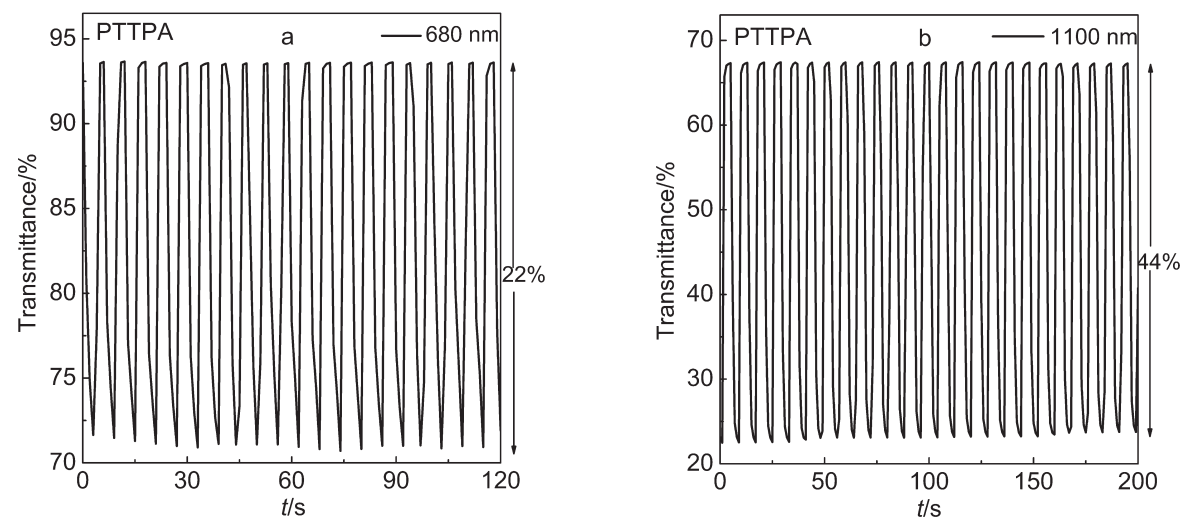

Fig.5 Electrochromic switching response for PTTPA film monitored at 680 and $1100 \mathrm{~nm}$ in $0.1 \mathrm{~mol} \cdot \mathrm{L}^{-1} \mathrm{TBAP}$ in DCM/ACN $(7: 3$, by volume) solution between -0.2 and $1.3 \mathrm{~V}$
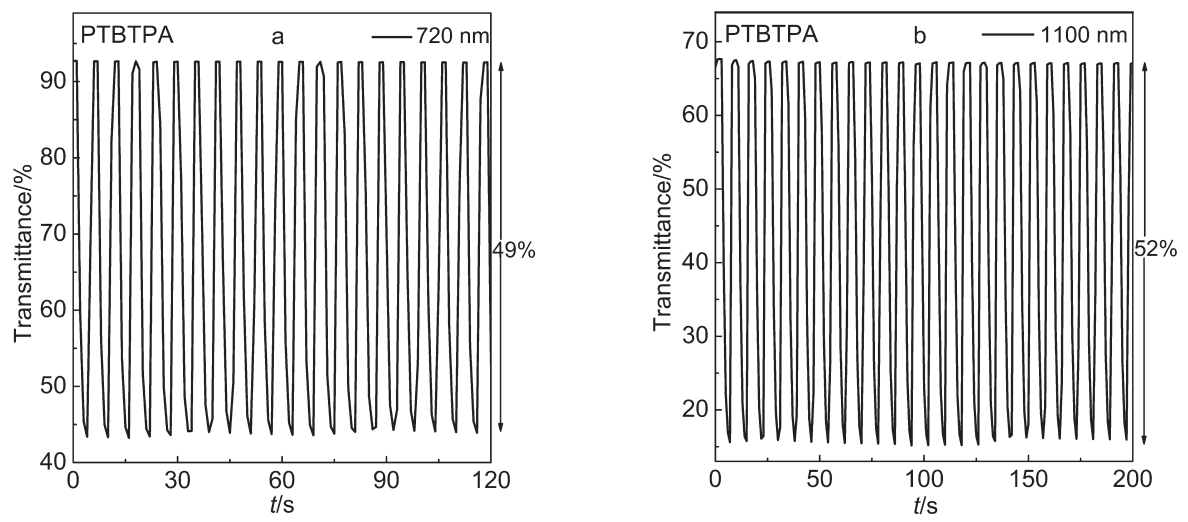

Fig.6 Electrochromic switching response for PTBTPA film monitored at 720 and $1100 \mathrm{~nm}$ in $0.1 \mathrm{~mol} \cdot \mathrm{L}^{-1} \mathrm{TBAP}$ in DCM/ACN $(7: 3$, by volume) solution between -0.2 and $1.4 \mathrm{~V}$

picted in Fig.5, the percentage transmittance changes $(\Delta T)$ between the neutral and oxidized states were $22 \%$ for $680 \mathrm{~nm}$ and $44 \%$ for $1100 \mathrm{~nm}$. And the switching times were $0.96 \mathrm{~s}$ at $680 \mathrm{~nm}$ and $0.93 \mathrm{~s}$ at $1100 \mathrm{~nm}$, respectively. While PTBTPA film was switched between -0.2 and $1.4 \mathrm{~V}$ (Fig.6). The percentage transmittance changes between the neutral and oxidized states were found to be $49 \%$ for $720 \mathrm{~nm}$ and $52 \%$ for $1100 \mathrm{~nm}$. And the switching times were $0.93 \mathrm{~s}$ at $720 \mathrm{~nm}$ and $0.91 \mathrm{~s}$ at $1100 \mathrm{~nm}$. These results showed that TBTPA could simultaneously achieve excellent level in optical contrasts and switching time.

The coloration efficiency (CE) was also an important characteristic for the electrochromic materials. It was defined as the change in the optical density $(\triangle \mathrm{OD})$ for the charge consumed per unit electrode area $(\Delta Q){ }^{28}$ The corresponding equations are given below:

$$
\begin{aligned}
& \Delta \mathrm{OD}=\lg \left(T_{\mathrm{b}} / T_{\mathrm{c}}\right) \\
& \eta=\Delta \mathrm{OD} / \Delta Q
\end{aligned}
$$

where $T_{\mathrm{b}}$ and $T_{\mathrm{c}}$ were the transmittances and colored states, respectively, and $\eta$ represented the coloration efficiency. CE values of PTBTPA and PTTPA were measured at the corresponding wavelength under full doped state (PTTPA: $108 \mathrm{~cm}^{2} \cdot \mathrm{C}^{-1}$ $(680 \mathrm{~nm}), 212 \mathrm{~cm}^{2} \cdot \mathrm{C}^{-1}(1100 \mathrm{~nm})$; PTBTPA: $198 \mathrm{~cm}^{2} \cdot \mathrm{C}^{-1}(720$ $\left.\mathrm{nm}), 285 \mathrm{~cm}^{2} \cdot \mathrm{C}^{-1}(1100 \mathrm{~nm})\right)$. Both of PTTPA and PTBTPA showed reasonable coloration efficiency. From the result of CE of the two polymers, PTBTPA showed higher coloration efficiency compared with PTTPA.

The above results demonstrated PTBTPA film possessed higher optical contrast than PTTPA film which may be attributed to stronger adhesion to electrode, better doping/dedoping process and smaller globule morphology. The EC performance is acceptable in EC devices, indicating that PTBTPA had its potentials to an efficient EC material.

\section{Conclusions}

The EC material TBTPA was synthesized and characterized. TBTPA presented better redox reversibility, excellent filmforming property and strong adhesion to electrode relative to the reported TTPA, which satisfied the basic requirement to achieve high EC performance. Furthermore, compared to reported PTTPA, PTBTPA displayed the enhanced EC performance with better contrast ratio of $44.7 \%$, percentage transmittance changes $(\Delta T)$ of $49 \%$ for $720 \mathrm{~nm}$ and $52 \%$ for $1100 \mathrm{~nm}$ and faster switching response of $0.93 \mathrm{~s}(720 \mathrm{~nm})$ and $0.91 \mathrm{~s}$ $(1100 \mathrm{~nm})$. Meanwhile, PTBTPA had higher coloration efficiency $\left(198 \mathrm{~cm}^{2} \cdot \mathrm{C}^{-1}(720 \mathrm{~nm}), 285 \mathrm{~cm}^{2} \cdot \mathrm{C}^{-1}(1100 \mathrm{~nm})\right)$. Besides, SEM images illustrated that the surface of PTBTPA film showed an accumulation state of clusters of globules, which 
was smaller than that of PTTPA. The excellent performance indicated that PTBTPA had its potentials to be an efficient EC material.

\section{References}

(1) Argun, A. A.; Aubert, P. H.; Thompson, B. C.; Schwendeman, I.; Gaupp, C. L.; Hwang, J.; Pinto, N. J.; Tanner, D. B.; MacDiarmid, A. G.; Reynolds, J. R. Chem. Mater. 2004, 16, 4401. doi: 10.1021/cm0496691

(2) Verghese, M. M.; Ram, M. K.; Vardhan, H.; Malhotra, B. D.; Ashraf, S. M. Polymer 1997, 38, 1625. doi: 10.1016/S0032-3861 (96)00655-6

(3) Beaupré, S.; Dumas, J.; Leclerc, M. Chem. Mater. 2006, 18 , 4011. doi: $10.1021 / \mathrm{cm} 060407 \mathrm{o}$

(4) Quinto, M.; Bard, A. J. J. Electroanal. Chem. 2001, 498, 67. doi: 10.1016/S0022-0728(00)00266-7

(5) Azens, A.; Granqvist, C. G. J. Solid State Electrochem. 2003, 7, 64.

(6) Heuer, H. W.; Wehrmann, R.; Kirchmeyer, S. Adv. Funct. Mater. 2002, 12, 89. doi: 10.1002/(ISSN)1616-3028

(7) Mortimer, R. J.; Dyer, A. L.; Reynolds, J. R. Displays 2006, 27, 2. doi: 10.1016/j.displa.2005.03.003

(8) Shah, J.; Brown, R. M., Jr. Appl. Microbiol. Biotechnol. 2005, 66, 352. doi: 10.1007/s00253-004-1756-6

(9) Sapp, A. S.; Sotzing, A. G.; Reynolds, J. R. Chem. Mater. 1998, 10, 2101. doi: 10.1021/cm9801237

(10) Chu, Z. Z.; Wang, D.; Zhang, C.; Zou. D. C. Acta Phys. -Chim. Sin. 2012, 28 (8), 2000. [初增泽, 王 丹, 张 超, 邹德春. 物理化学学报, 2012, 28 (8), 2000.] doi: 10.3866/PKU. WHXB201206071

(11) Pei, J.; Liang, M.; Chen, J.; Tao, Z. L.; Xu, W. Acta Phys. -Chem. Sin. 2008, 24 (11), 1950. [裴 娟, 梁 茂, 陈 军, 陶占良, 许 炜. 物理化学学报, 2008, 24 (11), 1950.] doi: 10.1016/ S1872-1508(08)60077-7

(12) Hagberg, D. P.; Edvinsson, T.; Marinado, T.; Boschloo, G.; Hagfeldt, A.; Sun, L. C. Chem. Commun. 2006, No. 21, 2245.

(13) Karthikeyan, C. S.; Peter, K.; Wietasch, H.; Thelakkat, M. Sol.
Energy Mater. Sol. Cells 2007, 91, 432. doi: 10.1016/j.solmat. 2006.10.006

(14) Nelson, R. F.; Adams, R. N. J. Am. Chem. Soc. 1968, 90, 3925. doi: $10.1021 / \mathrm{ja} 01017 \mathrm{a} 004$

(15) Lapkowskia, M.; Golba, S.; Soloduchoc, J.; Idzikc, K. Synthetic Met. 2009, 159, 2202. doi: 10.1016/j.synthmet.2009.09.005

(16) Zhang, C.; Wang, G. H.; Ouyang, M. J. Electroanal. Chem. 2011, 660, 45. doi: 10.1016/j.jelechem.2011.06.002

(17) Idzika, K.; Soloducho, J.; Lapkowski, M.; Golba, S.; Electrochim. Acta 2008, 53, 5665. doi: 10.1016/j.electacta. 2008.03.019

(18) Chiu, K. Y.; Su, T. X.; Li, J. H.; Lin, T. H.; Liou, G. S.; Cheng, S. H. J. Electroanal. Chem. 2005, 575, 95. doi: 10.1016/ j.jelechem.2004.09.005

(19) Cheng, X. F.; Zhao, J. S.; Cui, C. S.; Fu, Y. Z.; Zhang, X. X. J. Electroanal. Chem. 2012, 677-680, 24.

(20) Cho, J. S.; Uchida, K.; Yoshioka, N.; Yamamoto, K. Sci. Technol. Adv. Mat. 2004, 5, 697. doi: 10.1016/j.stam. 2004.03.006

(21) Ouyang, M.; Wang, G. H.; Zhang, C. Electrochim. Acta 2011, 56, 4645. doi: 10.1016/j.electacta.2011.02.103

(22) Gu, C.; Liu, H.; Hu, D. H.; Zhang, W. S.; Lv, Y.; Lu, P.; Lu, D.; Ma, Y. G. Macromol. Rapid Commun. 2011, 32, 1014. doi: 10.1002/marc.v32.13

(23) Sonmez, G.; Schwendeman, I.; Schottland, P.; Zong, K.; Reynolds, J. R. Macromolecules 2003, 36, 639. doi: 10.1021/ $\operatorname{ma} 021108 \mathrm{x}$

(24) Gu, C.; Dong, W. Y.; Yao, L.; Lv, Y.; Zhang, Z. B.; Lu, D.; Ma, Y. G. Adv. Mater. 2012, 24, 2413. doi: 10.1002/adma.201200559

(25) Sonmez, G. Chem. Commun. 2005, No. 42, 5251.

(26) Beyazyildirim, S.; Camurlu, P.; Yilmaz, D.; Gullu, M.; Toppare, L. J. Electroanal. Chem. 2006, 587, 235. doi: 10.1016/ j.jelechem.2005.11.018

(27) Akpinar, H.; Balan, A.; Baran, D.; ünver, E. K.; Toppare, L. Polymer 2010, 51, 6123. doi: 10.1016/j.polymer.2010.10.045

(28) Deepa, M.; Awadhia, A.; Bhandari, S. Phys. Chem. Chem. Phys. 2009, 11,5674 . 